\title{
Prediction of the rate of dust fall in Quetta city, Pakistan using seasonal ARIMA (SARIMA) modeling
}

\author{
Muhammad Sami ${ }^{1}$, Amir Waseem ${ }^{2}$, Yasmin Zahra Jafri ${ }^{3}$, Syed Haider Shah ${ }^{3}$, Muzafar Ahmed \\ Khan $^{4}$, Sher Akbar ${ }^{4}$, Masood Ahmed Siddiqui ${ }^{4}$ and Ghulam Murtaza ${ }^{5 *}$ \\ ${ }^{1}$ Department of Chemistry, Government Degree College, Khuzdar, Pakistan. \\ ${ }^{2}$ Department of Chemistry, COMSATS Institute of Information Technology, Abbottabad-22060, Pakistan. \\ ${ }^{3}$ Department of Statistics, University of Baluchistan, Quetta-87300, Pakistan. \\ ${ }^{4}$ Department of Chemistry, University of Balochistan, Quetta-87300, Pakistan. \\ ${ }^{5}$ Department of Pharmaceutical Sciences, COMSATS Institute of Information Technology, Abbottabad-22060, Pakistan.
}

\section{Accepted 23 November, 2011}

\begin{abstract}
The components and quantities of atmospheric dust fallout have been reported to be the pollution indicator of large urban areas. The multiplicity and complexity of sources of atmospheric dusts in urban regions has put forward the need for source apportionment of these sources in order to indicate) their contribution to a specific environmental receptor. The study presented here is focused on the investigation of the rate of dust fall in Quetta valley. Having used seasonal autoregressive integrated moving average ARIMA (SARIMA) modeling, the prediction equations were developed to forecast the seasonal rate of dust fall at three different locations out of 10 selected sites in Quetta from 2004 to 2008. In terms of deduced statistical equations, the findings could help to predict, abate, minimize or even control the pollutants, predominantly the heavy and toxic metals present in the dust particulates that are studied by this sort of research work. Seasonal ARIMA (SARIMA) model was found to be a better forecaster of the rate of dust fall having vitally analyzed the entire stochastic models on diverse climatic parameters.
\end{abstract}

Key words: Particulate matter, rate of dust fall, heavy metals, autoregressive integrated moving average (ARIMA), stochastic modeling, Markov transition matrix (MTM).

\section{INTRODUCTION}

The bowl shaped Quetta Valley is about $1,650 \mathrm{~m}$ above mean sea level, and is bounded by the Murdar Mountain ranges with peak height of $3,134 \mathrm{~m}$. The Chiltan Mountain (peak height 3,261 m) almost parallels it by 10 to $16 \mathrm{~km}$ on the east and west of the valley. Somewhat farther are the mountain ranges of Zarghoon (peak height $3,519 \mathrm{~m}$ ) and Takatoo (peak height 3,401 m) enclosing the Valley along the Northeast and Northwest directions. Quetta is sited at Latitude 29 $48^{\prime}$ to $3025^{\prime}$ North and Longitude 6693' to 6797' East having an area of about

${ }^{*}$ Corresponding author. E-mail: gmdogar356@gmail.com. Tel: 92-0314-2082826. Fax: 92-62-9255565.
$2,653 \mathrm{~km}^{2}$. Heavy snowfalls commonly occur in the valley and on the high mountains which sporadically have low humidity occurring during December, January and February. Thin covers of wild herbal plants grow in uncultivated regions. Quetta Valley has got all four seasons: Spring (February, March and April), summer (May, June and July), autumn (August, September and October) and winter (November, December and January), having sub-tropical climate. Mainly, its landscape has plains. Limestone is the major part of the sedimentary rocks around the valley. Normally, $200 \mathrm{~mm}$ average annual precipitation happens in the valley usually in winter. The mean annual temperature is around $64^{\circ} \mathrm{F}$. The mean summer and winter temperatures are around 78 and $40^{\circ} \mathrm{F}$, respectively. About $27^{\circ} \mathrm{F}$ min imum 
Table 1. Classification - American Standard Test Method ASTM D1739 Dust = Milligrams/day/square meter.

\begin{tabular}{lcc}
\hline $\begin{array}{l}\text { Classification by Department of } \\
\text { Environmental Affairs and Tourism }\end{array}$ & ASTM equivalent & $\begin{array}{l}\text { S. A. German Din Air Quality } \\
\text { Monthly Limit }\end{array}$ \\
\hline Slight & $<250$ & 650 non industrial limit \\
Moderate & $251-500$ & $1300 \geq$ industrial limit \\
\hline Heavy & $\begin{array}{c}501-1200 \\
>1200\end{array}$ & 1200 \\
Very heavy & &
\end{tabular}

average temperature in January and $96{ }^{\circ} \mathrm{F}$ as the maximum average temperature in July have been recorded (Sami, 2009). Diurnal variations for wind speeds have been used to adjust the months of all four seasons. $58 \mathrm{~mm}$ rainfall is recorded normally in winter season in Quetta Valley due to the peculiar wind patterns unlike the rest part of the country (Pakistan). Similarly a little less than $13 \mathrm{~mm}$ rainfall is usually experienced in summer, again, dissimilar to the rest of the country, as about $90 \%$ part of Balochistan region is not hit by 'monsoon', a wind pattern, which causes heavy downpour in Bengal, India and most parts of Pakistan. Generally, in normal conditions, Quetta experiences maximum temperature of about $35^{\circ} \mathrm{C}$ and minimum $-6^{\circ} \mathrm{C}$ in the summer and winte $r$ seasons respectively (Sami, 2009).

The population of Quetta is recorded to be 1.5 million officially, yet unofficially it is claimed that it has even crossed the figures of 2.5 million. Rickshaws are the major means of public transport $(\geq 5000)$. Besides the Stone Age, local buses and the haphazard population of both humans and traffic, lack of planning, and corruption trigger the pollution from bad to worst (Sami, 2009).

During our research, settling dust particulates samples were collected for the period of five years 2004 to 2008 from ten different sites of Quetta city depending on their locations, traffic population, height, developed and underdeveloped areas. Dust samples were collected on daily basis (after every $24 \mathrm{~h}$ ) for the year 2004 due to the dropping drought spell. However, samples of settled dust particulates were collected within the gap of every one calendar month for the next four years 2005 to 2008. With the collected data, the rate of dust fall was calculated for all the 5 years and the concentration of heavy/toxic metals/elements lead $(\mathrm{Pb})$, zinc $(\mathrm{Zn})$, manganese $(\mathrm{Mn})$, nickel $(\mathrm{Ni})$, chromium $(\mathrm{Cr})$, cobalt $(\mathrm{Co})$ was detected by using Atomic Adsorption Spectrophotometer (AAS). The concentration of sodium $(\mathrm{Na})$ and potassium $(\mathrm{K})$ was determined by Flame Photometer besides the sizes of particulates. The findings showed immense concentrations of dust fall, enormous amount of heavy toxic/heavy metals particularly, $\mathrm{Pb}$, and the vast variations in the sizes of dust particulates (specifically, $\mathrm{PM}_{10}$ ) contrary to the international set standards (Sami et al., 2006). Some stochastic equations were derived in order to predict the rate of dust fall in Quetta in future, keeping in view the more than enough concentration of almost all heavy/toxic elements, the extreme variation in the size of particulates (particularly of $\mathrm{PM}_{10}$ ) and the massive rate of dust fall in relation to the international set standards (Table 1) (ASTM, 2004).

In order to build up simulation and forecasting, hourly average wind speed, annual average and monthly rate of dust fall series on five year data, that is, from 2004 to 2008 of Quetta, Pakistan stochastic time series model, (autoregressive integrated moving average) ARIMA (p.q), non-seasonal ARIMA and seasonal ARIMA (SARIMA) models were built up. Various basic characteristics of wind rate including autocorrelation, non-Gaussian distribution and non-stationarity were considered by Stochastic Time Series Models. By fitting ARMA method to wind speed data, the positive correlation between successive wind speed observations was considered. To eliminate the scattering of transformed data (stationary data, that is, data without chaos), the data are regularized to make their divisions more or less Gaussian and standardized. To observe the forecasts and their reliance on lead times, diurnal variations are considered. Seasonal ARIMA model is considered to account for diurnal variations. We studied the seasonal ARIMA (SARIMA) and its prediction equations for each month of the five years data. ARIMA was good enough to forecast comparatively short and long range reliable values, used for the five years, that is, 2004 to 2008 data of dust fall, average humidity, rainfall, maximum and minimum temperatures, even though its prediction equations did not work efficiently, in providing non-stationarity or chaos in data, stochastic simulator in the ARIMA processes. ARIMA models were used (Kumar et al., 2004; Kumar and Jain 2010) to forecast daily average surface pressures. The study of Badescu has extreme similarity with ours as the surface pressure certainly affected the rate of dust fall and certainly the concentration of pollutants at different sites. Such considerations will indirectly consider our SARIMA model which showed that the statistical analysis of ambient air pollution was carried out (Durdu, 2010; Kumar et al., 2004; Kumar and Jain, 2010) in Delhi. For the prediction of various pollutants 
and repairable suspended particulate matter, a state space model was developed by using Kalmin filter formulation. The model was found quite applicable. The Auto-Regressive (ARX) model with the exogenous input which it used was not adequate for our analysis. The ARIMA modeling was discarded because the rate of dust fall and the concentration of various pollutants (Durdu, 2010) followed a random nature of non-stationarity in wind speeds. Thus, we developed ARIMA (Sami, 2009) and SARIMA models for dust fall rate and indeed their forecasting equations. In ARX modeling, an incredible scattering of predicted data was noted. Time series of the urban air pollution analysis which was done by using Artificial Neural Network (ANN) and ARIMA models is insufficient. On the basis of root mean square estimation and other several statistical tests, ANN was found to be better than ARIMA. In our views, due to diurnal (seasonal) variations, the ARIMA and SARIMA models were considered to be relatively better than the ANN model. It was noted in our study that with the interrelationship between ARIMA and SARIMA, the diurnal variations could be considered. Having used ARIMA, crop evapotranspiration time series simulation model was developed (Hamdi et al., 2008). In most of the reported literature, this reflects the strength and validity of ARIMA model.

Owing to the interest in its rate of deposition, which generally proves to be disastrous, time series modeling of dust fall has been the subject of many deliberations. A time series model is required when the records of dust fall are incomplete or of a too short duration, or the handling and storage of large values of the data are not wanted. By and large, the simulation is derived from simulations of wind speed since dust fall is a sign of wind velocity, atmospheric pressure, geography and topography of the area. Monto Carlo techniques which depend exclusively upon the anticipated factors of the trivial distribution of wind speeds, dust fall simulations could be done with it.

Some important contributions from modeling and simulation point of view were made (Cragg et al., 1999; Aguiar and Collares-Pereira, 1992; Mora-Lopez and Sidrach-de-Cardona, 1998) having generated an hourly series of global radiation with the simultaneous usages of stochastic simulation by ARIMA modeling of solar radiation, a time dependent autoregressive Gaussian model (TAG) for generating synthetic hourly radiation, and the multiplicative autoregressive moving average (ARMA) models. Lalarukh and Jafri used an ARMA process on hourly global radiation data (Kamal and and Jafri, 1999). They performed the synthetic sequences of hourly global solar irradiation for Quetta, Pakistan as well as Stochastic modeling through Markov Transition Matrix (MTM). Compared to ARMA modeling, MTM (Kamal and Jafri, 1997) approach was found to be pretty better as a simulator by them.
Kumar et al. (2010) and Jain and Lungu (2002) reported the ARIMA forecasting of ambient air pollutants. They used a combination of diverse information criterion, namely, Akaike Information Criterion (AIC), Hannon-Quin Infor-mation Criterion (HIC), Bayesian Information Criterion (BIC), and Final Prediction Criterion (FPE) for autocorrelation function (ACF) and partial autocorrelation function (PACF) in order to check the validity of suitable orders of autoregressive (p) and moving average (q). They, however, did not employ the chi-square test on the basis of the orders of autoregressive and moving average, which of course, considers the minimum $\chi^{2}$ for all possible combinations. To make ARMA (a non-stationary stochastic model) stationary, standardization of mean and standard deviation is a pre-requisite. We, however, in our present study, employed all such criteria and proposed suitable ARIMA and SARIMA models for the tests.

Durdu (2010) used ARIMA and SARIMA models (stochastic approaches) for time series forecasting of boron. He used only AIC for orders of model parameters, that is, autoregressive ( $p)$ and moving average (q) both for ARIMA and SARIMA. He compared the mean and variance of observed data with the predicted data and suggested that the ARIMA modeling approach was suitable when compared to SARIMA. His approach is confined only to very simple applications of ARIMA and SARIMA models whereas our analysis in the present study deals with all possible generalized ARIMA and SARIMA models. We developed prediction equations for all generalized cases for ARIMA and SARIMA models.

The ways in which the hourly forecasting of average wind rate could be done were suggested by Brown et al. (1984, 1982), keeping in mind the auto interconnected nature of wind velocity, the diurnal non-stationarity and non-Gaussian shape of wind velocity division. The requirement for standardization to eliminate diurnal nonstationarity was also pointed out in the earlier study of Brown et al. (1982). As declared in a paper (Jafri et al., 1989) that standardization relates to reproducing of an even profile, such as that of a Gaussian distribution that is achieved after converting a non-Gaussian form to an almost Gaussian shape, that is, taking speckled data points close to the sketch diurnal variations in wind speed happens as a natural phenomenon (Kamal and Jafri, 1996).

In fact, a bigger class of seasonal models contains ARIMA models (Blanchard and Desrochers, 1984). The linear ARIMA models and feed forward artificial neural networks (FFANN) were studied (Sfetsos, 2002). It was found that from the minimization of the assessment set error in the ARIMA process the model arrangement is chosen. Multi-step forecasting and the consequent averaging to produce mean hourly predictions of wind statistics was suggested by them. Jain and Lungu (2002) extensively studied the ARIMA models. They equally considered non-seasonal and seasonal ARIMA models by 
using stochastic parts. They also decided to calculate the perseverance patterns if any, of the stochastic components.

A new description of an existing time series modeling method (McWilliams and Sprevak, 1982a), from which the distribution of wind velocities and wind directions are obtained (Box and Jenkins, 1976), was explained as well (McWilliams and Sprevak, 1982b). The diurnal variations observed in wind speed by their model were incorporated in such a manner that the time series of wind speed component remained stationary. As far as the second order statistics were concerned, the sample autocorrelation functions for the series had the same stochastic trend, resultantly plummeting the problem to modeling single Gaussian series. To justify the diurnal variations, this model was accurate for autocorrelation functions. The aforementioned studies did not use the transformation of hourly average wind speed; that is the one point which is obvious. They rather measured the annual deterministic variation $\mu(\mathrm{t})$ and $\sigma^{2}(\mathrm{t})$ in its place in order to justify diurnal variation of wind velocity, which is modeled by harmonic series representation. With reference to our inference, diurnal variation (Brown et al., 1982) should be engaged in model development in a manner analogous to McWilliams and Sprevak (McWilliams and Sprevak 1982b).

MINITAB (version 11) was used for non-seasonal ARIMA modeling and simulation. In order to model a special class of non-stationary series, ARIMA models were used and to incorporate cyclic components in the models, seasonal ARIMA (SARIMA) models were used. For forecasting a time series, which can be stationarized by transformations such as differencing and logging, theoretically, ARIMA models were said to be the most general class of models parsimoniously. SARIMA has the same structure as does ARIMA. It is the most powerful tool for deciphering the cyclic components especially, of diurnal variations, as a consequence of which, short term predictions acquire more reliability as compared to ARIMA. Moreover, the long term predictions are automatically adjusted in terms of performance and accuracy. The seasonal models are used on monthly and annually average rates of dust fall data from 2004 to 2008. Keeping in view the primary minimum chi- squared value at $5 \%$ confidence gap, the greatest choice is selected.

\section{THEORY}

To model a special class of non-stationary time series, ARIMA models were used. Likewise to incorporate cyclic components in models, seasonal ARIMA (SARIMA) model was used. The time series were split into stochastic and deterministic constituents. Through Monto Carlo simulations, the proportion of variance for each component was modeled. The stochastic component was used to analyze persistence in the time series (Box and Jenkins, 1976).

In order to check the validity of the suitable orders of $p$ and $q$, the general non-seasonal ARIMA model is autoregressive and operates on the $d t h$ differences of $Z_{t}$, where $\left\{Z_{t}\right\}$ are time series values for $t=1,2, \ldots, N$ and $N$ is number of observations. Defining:

$\mathrm{B}^{\mathrm{s}} \mathrm{Z}_{\mathrm{t}}=\mathrm{Z}_{\mathrm{t}-\mathrm{s}}, \quad \nabla_{\mathrm{s}}=\left(1-\mathrm{B}^{\mathrm{s}}\right), \nabla_{s}^{d}=\left(1-\mathrm{B}^{\mathrm{s}}\right)^{\mathrm{d}}$

where $d=0,1, \ldots, B$ is the backward shift operator, $s$ is the period of the season ( $s=12$ in our present case for each month) and $\nabla$ is the difference operator. The general non-seasonal ARIMA model could be written as:

$\Phi p(B) Z_{t}=\theta_{q}(B) a_{t}$

where $\left\{a_{t}\right\}$ are residuals, and

$\Phi_{p}(B)=1-\Phi_{1} B-\Phi_{2} B^{2}-, \ldots,-\Phi_{p} B^{p}$

$\theta_{q}(B)=1-\theta_{1} B-\theta_{2} B^{2}-, \ldots,-\theta_{q} B^{q}$

are the polynomials of order $p$ and $q$, respectively. The error ' $e$ ' in our prediction equation could be adjusted automatically with lead times, t.

Time series prediction with harmonic analysis can also be accomplished (Jain and Lungu, 2002, Jafri et al., 2012). Theories on regression analysis time series have long been established (Gujarati, 1988; Chapra and Canale, 1990; Rawlings et al., 1988). Equation (2) was modified by Box and Jenkins (1976) to account for the seasonal dependence. This yielded:

$\Phi\left(\mathrm{B}^{\mathrm{s}}\right) \nabla_{s}^{d} \mathrm{Z}_{\mathrm{t}}=\theta_{\mathrm{Q}}\left(\mathrm{B}^{\mathrm{s}}\right) \mathrm{e}_{\mathrm{t}}$

where $\left\{e_{t}\right\}$ are normal random deviates,

$\Phi_{\mathrm{P}}\left(\mathrm{B}^{\mathrm{s}}\right)=1-\Phi_{1} \mathrm{~B}^{\mathrm{s}}-\Phi_{2} \mathrm{~B}^{2 \mathrm{~s}}-, \ldots,-\Phi_{\mathrm{P}} \mathrm{B}^{\mathrm{Ps}}$

and

$\theta_{Q}(B)=1-\theta_{1} B^{s}-\theta_{2} B^{2 s}-, \ldots,-\theta_{Q} B^{Q s}-$

are the seasonal autoregressive and moving average operators of order $p$ and $q$ respectively. As $e_{t}$ is not necessarily independent of $e_{t-j}, j=1,2, \ldots$ we propose the following relation for the e-values:

$\Phi_{\mathrm{p}}(\mathrm{B}) \nabla^{d} \mathrm{e}_{\mathrm{t}}=\theta_{\mathrm{q}}(\mathrm{B}) \mathrm{a}_{\mathrm{t}}$

where $a_{t}$ is white noise (uncorrelated random variable with mean zero and variance $\sigma^{2}$ ); combining Equations (11) and (14) for SARIMA model, that is, SARIMA $(p, d, q)(P, D, Q)_{s}$, we get a multiplicative SARIMA model of order $(p, d, q) \times(P, D, Q)_{s}$ of the form:

$\Phi_{\mathrm{P}}\left(\mathrm{B}^{\mathrm{s}}\right) \Phi_{\mathrm{P}}(\mathrm{B}) \nabla_{s}^{D} \nabla^{d} \mathrm{Z}_{\mathrm{t}}=\theta_{\mathrm{Q}}\left(\mathrm{B}^{\mathrm{s}}\right) \theta_{\mathrm{q}}(\mathrm{B}) \mathrm{a}_{\mathrm{t}}$

\section{RESULTS AND DISCUSSION}

Three locations were taken bearing in mind their optimum values of rate of dust fall, such as Jinnah road (sampling site $h$ ), Chiltan road (sampling site $f$ ) and Satellite town (sampling site d) as shown in map reported previously (Sami et al., 2006), that is, Gawalmandi received the maximum average amount of dust fall particulates, while at a T.B. Sanatorium, the minimum average amount of dust fall particles was recorded. In order to compare the 
Table 2. SARIMA sampling point $h$ for spring.

\begin{tabular}{|c|c|c|c|c|c|c|c|}
\hline Month & $\begin{array}{c}\text { Seasonal SARIMA } \\
\text { (p.d.q.) }\end{array}$ & $\chi^{2} 0.05$ & d.f & $\begin{array}{c}A R(1) \\
\Phi\end{array}$ & $\begin{array}{c}\text { MA (1) } \\
0\end{array}$ & $\begin{array}{c}\text { SMA (12) } \\
0\end{array}$ & $\begin{array}{l}\text { Constant } \\
\text { (a) }\end{array}$ \\
\hline \multirow{5}{*}{ February } & $(0,1,1) \times(0,1,1) 12$ & 10.8 & 10 & - & 0.2454 & -1.9938 & .4132 \\
\hline & $(0,0,0) \times(0,1,0) 12$ & - & - & - & - & - & - \\
\hline & $(0,1,0) \times(0,1,0) 12$ & - & - & - & - & - & - \\
\hline & $(1,0,0) \times(0,1,0) 12$ & 5.3 & 11 & 0.3136 & - & - & -0.3112 \\
\hline & $(1,0,1) \times(0,1,1) 12$ & 5.6 & 9 & -0.6958 & -1.175 & 0.2871 & -0.1754 \\
\hline
\end{tabular}

Prediction equation follows SARIMA $(1,0,0) \times(0,1,0) 12$ where the number 12 refers to twelve months as seasonal duration over the year. SAR $(1,0,0) \times(0,1,0) 12$ is a seasonal random walk model. The forecasting equation is: $x(t)=a+x(t-$ $12)+\Phi(x(t-1)-x(t-12))$. The seasonal random walk(SRW) is an alternate to seasonal random trend (SRT) model

\begin{tabular}{llcccccc}
\hline \multirow{5}{*}{ March } & $(0,1,1) \times(0,1,1) 12$ & 19.6 & 10 & - & 9.182 & - & .04549 \\
& $(0,0,0) \times(0,1,0) 12$ & - & - & - & - & - & - \\
& $(0,1,0) \times(0,1,0) 12$ & - & - & - & - & - & - \\
& $(1,0,0) \times(0,1,0) 12$ & 10.9 & 11 & -.3918 & - & - & -.00698 \\
& $(1,0,1) \times(0,1,1) 12$ & 6.6 & 9 & -.2276 & 1.1200 & - & -.00668 \\
\hline
\end{tabular}

Prediction equation follows SARIMA $(1,0,0) \times(0,1,0) 12$ where the number 12 is an important version of seasonal exponential smoothing (SES) model, that is, with a constant. The forecasting equation for this model is: $x(t)=2+x(t-12)+$ $\Phi\{\mathrm{x}(\mathrm{t}-1)-\mathrm{x}(\mathrm{t}-12)\}-\theta \mathrm{e}(\mathrm{t}-1)-\Theta \mathrm{e}(\mathrm{t}-12)+\theta \Theta e(\mathrm{t}-13)$

\begin{tabular}{llcccccc}
\hline & $(0,1,1) \times(0,1,1) 12$ & 180.9 & 10 & - & 0.2025 & -2.2682 & -3.723 \\
April & $(0,0,0) \times(0,1,0) 12$ & - & - & - & - & - & - \\
& $(0,1,0) \times(0,1,0) 12$ & - & - & - & - & - & - \\
& $(1,0,0) \times(0,1,0) 12$ & 30.5 & 11 & 0.8548 & - & - & 1.789 \\
& $(1,0,1) \times(0,1,1) 12$ & 60.8 & 9 & 0.7796 & -0.0034 & 1.2420 & 3.2443 \\
\hline
\end{tabular}

Prediction equation follows SARIMA $(1,0,0) \times(0,1,0) 12$ where the number 12 refers to twelve months as seasonal duration over the year. SAR $(1,0,0) \times(0,1,0) 12$ is a seasonal random walk model. The forecasting equation is: $x(t)=a+x(t-12)+$ $\Phi(\mathrm{x}(\mathrm{t}-1)-\mathrm{x}(\mathrm{t}-12))$. The seasonal random walk(SRW) is an alternate to seasonal random trend (SRT) model

statistical variations in between the optimum values, Satellite town (sampling site d) was taken as third site, which facilitated us to get the statistical variations regarding mean values of the optimum rate of dust fall. Tables 2 to 13 that have prediction equations got for each month of every season show the seasonal SARIMA classification on the basis of all four seasons of Quetta from spring to winter having their corresponding months for all the three selected sites of $d, f$, and $h$ respectively.

\section{Conclusions}

In order to predict the gravity of such situations in future and take remedial measures to curtail the dust fall and toxic/heavy metals, the statistical SARIMA modeling and its prediction equations were developed by us.

The prediction equations for the rate of dust fall for each month classified in relation to the seasons for SARIMA are given subsequently.

We inferred from this study that the statistical modeling of the SARIMA prediction equations of maximum dust fall at receiving site ' $h$ ' are: Spring (Table 2) [February
$\mathrm{x}(\mathrm{t})=\mathrm{a}+\mathrm{x}(\mathrm{t}-12)+\Phi(\mathrm{x}(\mathrm{t}-1)-\mathrm{x}(\mathrm{t}-12))$, March $\mathrm{x}(\mathrm{t})=2+\mathrm{x}(\mathrm{t}-12)+$ $\Phi\{\mathrm{x}(\mathrm{t}-1)-\mathrm{x}(\mathrm{t}-12)\}-\theta \mathrm{e}(\mathrm{t}-1)-\Theta \mathrm{e}(\mathrm{t}-12)+\theta \Theta \mathrm{e}(\mathrm{t}-13)$ and April $\mathrm{x}(\mathrm{t})=\mathrm{a}+\mathrm{x}(\mathrm{t}-12)+\Phi(\mathrm{x}(\mathrm{t}-1)-\mathrm{x}(\mathrm{t}-12))]$; summer (Table 3) $[$ May $x(t)=2+x(t-12)+\Phi\{x(t-1)-x(t-12)\}-\theta e(t-1)-\Theta e(t-$ 12) $+\theta \Theta e(t-13)$, June $x(t)=2+x(t-12)+\Phi\{x(t-1)-x(t-12)\}$ $-\theta \mathrm{e}(\mathrm{t}-1)-\Theta \mathrm{e}(\mathrm{t}-12)+\theta \Theta e(\mathrm{t}-13)$ and July $\mathrm{x}(\mathrm{t})=\mathrm{a}+\mathrm{x}(\mathrm{t}-$ 12) $+\Phi(x(t-1)-x(t-12))]$; autumn (Table 4) [August $\mathrm{x}(\mathrm{t})=\mathrm{a}+\mathrm{x}(\mathrm{t}-12)+\Phi(\mathrm{x}(\mathrm{t}-1)-\mathrm{x}(\mathrm{t}-12))$, September $\mathrm{x}(\mathrm{t})=2+\mathrm{x}(\mathrm{t}-12)$ $+\Phi\{\mathrm{x}(\mathrm{t}-1)-\mathrm{x}(\mathrm{t}-12)\}-\theta \mathrm{e}(\mathrm{t}-1)-\Theta \mathrm{e}(\mathrm{t}-12)+\theta \Theta \mathrm{e}(\mathrm{t}-13)$ and October $\mathrm{x}(\mathrm{t})=2+\mathrm{x}(\mathrm{t}-12)+\Phi\{\mathrm{x}(\mathrm{t}-1)-\mathrm{x}(\mathrm{t}-12)\}-\theta \mathrm{e}(\mathrm{t}-1)$ $-\Theta \mathrm{e}(\mathrm{t}-12)+\theta \Theta e(\mathrm{t}-13)]$, and winter (Table 5) [November $\mathrm{x}(\mathrm{t})=2+\mathrm{x}(\mathrm{t}-12)+\Phi\{\mathrm{x}(\mathrm{t}-1)-\mathrm{x}(\mathrm{t}-12)\}-\theta \mathrm{e}(\mathrm{t}-1)-\Theta \mathrm{e}(\mathrm{t}-12)+$ $\theta \Theta e(t-13)$, December $x(t)=2+x(t-12)+\Phi\{x(t-1)-x(t-12)\}$ $-\theta \mathrm{e}(\mathrm{t}-1)-\Theta \mathrm{e}(\mathrm{t}-12)+\theta \Theta \mathrm{e}(\mathrm{t}-13)$ and January $\mathrm{x}(\mathrm{t})=\mathrm{a}+\mathrm{x}(\mathrm{t}-$ $12)+\Phi(x(t-1)-x(t-12))]$ respectively.

Similarly, the statistical modeling of SARIMA prediction equations for our second minimum dust fall receiving site ' $f$ ' are in the order of: Spring (Table 6) [February $\mathrm{x}(\mathrm{t})=\mathrm{x}(\mathrm{t}-$ 12) $+x(\mathrm{t}-1)-\mathrm{x}(\mathrm{t}-13)-\theta \mathrm{e}(\mathrm{t}-1)-\Theta \mathrm{e}(\mathrm{t}-12)+\Theta \theta \mathrm{t}(\mathrm{t}-13)$, March $\mathrm{x}(\mathrm{t})=\mathrm{x}(\mathrm{t}-12)+\mathrm{x}(\mathrm{t}-1)-\mathrm{x}(\mathrm{t}-13)-\theta \mathrm{e}(\mathrm{t}-1)-\Theta e(\mathrm{t}-12)+\Theta \theta \mathrm{e}(\mathrm{t}-13)$ and April $\quad x(t)=x(t-12)+x(t-1)-x(t-13)-\theta e(t-1)-\Theta e(t-12)+\Theta \theta e(t-$ 13)] ; summer (Table 7) [May $x(t)=x(t-12)+x(t-1)-x(t-13)-$ 
Table 3. SARIMA sampling point $\mathrm{h}$ for summer.

\begin{tabular}{|c|c|c|c|c|c|c|c|}
\hline Month & $\begin{array}{c}\text { Seasonal SARIMA } \\
\text { (p.d.q.) }\end{array}$ & $\chi^{2} 0.05$ & d.f & $\begin{array}{c}A R(1) \\
\Phi\end{array}$ & $\begin{array}{c}\text { MA (1) } \\
0 \\
\end{array}$ & $\begin{array}{c}\text { SMA (12) } \\
0\end{array}$ & $\begin{array}{c}\text { Constant } \\
\text { (a) }\end{array}$ \\
\hline \multirow{5}{*}{ February } & $(0,1,1) \times(0,1,1) 12$ & 10.8 & 10 & - & 0.2454 & -1.9938 & 0.4132 \\
\hline & $(0,0,0) \times(0,1,0) 12$ & - & - & - & - & - & - \\
\hline & $(0,1,0) \times(0,1,0) 12$ & - & - & - & - & - & - \\
\hline & $(1,0,0) \times(0,1,0) 12$ & 5.3 & 11 & 0.3136 & - & - & -.3112 \\
\hline & $(1,0,1) \times(0,1,1) 12$ & 5.6 & 9 & -0.6958 & -1.175 & 0.2871 & -0.1754 \\
\hline
\end{tabular}

Prediction equation follows SARIMA $(1,0,0) \times(0,1,0) 12$ where the number 12 refers to twelve months as seasonal duration over the year. SAR $(1,0,0) \times(0,1,0) 12$ is a seasonal random walk model. The forecasting equation is: $x(t)=a+x(t-12)+\Phi(x(t-$ $1)-x(t-12))$. The seasonal random walk(SRW) is an alternate to seasonal random trend (SRT) model

\begin{tabular}{llllllll}
\hline \multirow{5}{*}{ March } & $(0,1,1) \times(0,1,1) 12$ & 19.6 & 10 & - & 9.182 & - & 0.04549 \\
& $(0,0,0) \times(0,1,0) 12$ & - & - & - & - & - & - \\
& $(0,1,0) \times(0,1,0) 12$ & - & - & - & - & - & - \\
& $(1,0,0) \times(0,1,0) 12$ & 10.9 & 11 & -0.3918 & - & - & -0.00698 \\
& $(1,0,1) \times(0,1,1) 12$ & 6.6 & 9 & -0.2276 & 1.1200 & - & -0.00668 \\
\hline
\end{tabular}

Prediction equation follows SARIMA $(1,0,0) \times(0,1,0) 12$ where the number 12 is an important version of seasonal exponential smoothing (SES) model, that is, with a constant. The forecasting equation for this model is: $x(t)=2+x(t-12)+$ $\Phi\{\mathrm{x}(\mathrm{t}-1)-\mathrm{x}(\mathrm{t}-12)\}-\theta \mathrm{e}(\mathrm{t}-1)-\Theta \mathrm{e}(\mathrm{t}-12)+\theta \Theta \mathrm{e}(\mathrm{t}-13)$

\begin{tabular}{llcccccc}
\hline & $(0,1,1) \times(0,1,1) 12$ & 18.9 & 10 & - & 0.2025 & -2.2682 & -3.723 \\
April & $(0,0,0) \times(0,1,0) 12$ & - & - & - & - & - & - \\
& $(0,1,0) \times(0,1,0) 12$ & - & - & - & - & - & - \\
& $(1,0,0) \times(0,1,0) 12$ & 3.5 & 11 & 0.8548 & - & - & 1.789 \\
& $(1,0,1) \times(0,1,1) 12$ & 6.8 & 9 & 0.7796 & -0.0034 & 1.2420 & 3.2443 \\
\hline
\end{tabular}

Prediction equation follows SARIMA $(1,0,0) \times(0,1,0) 12$ where the number 12 refers to twelve months as seasonal duration over the year. SAR $(1,0,0) \times(0,1,0) 12$ is a seasonal random walk model. the forecasting equation is: $x(t)=a+x(t-12)+\Phi(x(t-$ $1)-x(t-12))$. The seasonal random walk(SRW) is an alternate to seasonal random trend (SRT) model

Table 4. SARIMA sampling point $h$ for autumn.

\begin{tabular}{|c|c|c|c|c|c|c|c|}
\hline Month & $\begin{array}{l}\text { Seasonal SARIMA } \\
\text { (p.d.q.) }\end{array}$ & $\chi_{0.05}^{2}$ & d.f & $\begin{array}{c}A R(1) \\
\Phi\end{array}$ & $\begin{array}{c}\text { MA (1) } \\
0\end{array}$ & $\begin{array}{c}\text { SMA (12) } \\
0\end{array}$ & Constant (a) \\
\hline \multirow{5}{*}{ February } & $(0,1,1) \times(0,1,1) 12$ & 10.8 & 10 & - & 0.2454 & -1.9938 & 0.4132 \\
\hline & $(0,0,0) \times(0,1,0) 12$ & - & - & - & - & - & - \\
\hline & $(0,1,0) \times(0,1,0) 12$ & - & - & - & - & - & - \\
\hline & $(1,0,0) \times(0,1,0) 12$ & 5.3 & 11 & 0.3136 & - & - & -0.3112 \\
\hline & $(1,0,1) \times(0,1,1) 12$ & 5.6 & 9 & -0.6958 & -1.175 & 0.2871 & -0.1754 \\
\hline
\end{tabular}

Prediction equation follows SARIMA $(1,0,0) \times(0,1,0) 12$ where the number 12 refers to twelve months as seasonal duration over the year. SAR $(1,0,0) \times(0,1,0) 12$ is a seasonal random walk model. The forecasting equation is: $x(t)=a+x(t-12)+\Phi(x(t-1)-x(t-12))$. The seasonal random walk(SRW) is an alternate to seasonal random trend (SRT) model

\begin{tabular}{llcccccc}
\hline \multirow{4}{*}{ March } & $(0,1,1) \times(0,1,1) 12$ & 19.6 & 10 & - & 9.182 & - & 0.04549 \\
& $(0,0,0) \times(0,1,0) 12$ & - & - & - & - & - & - \\
& $(0,1,0) \times(0,1,0) 12$ & - & - & - & - & - & - \\
& $(1,0,0) \times(0,1,0) 12$ & 10.9 & 11 & -0.3918 & - & - & -0.00698 \\
& $(1,0,1) \times(0,1,1) 12$ & 6.6 & 9 & -.02276 & 1.1200 & - & -0.00668 \\
\hline
\end{tabular}

Prediction equation follows SARIMA $(1,0,0) \times(0,1,0) 12$ where the number 12 is an important version of seasonal exponential smoothing (SES) model, that is, with a constant. The forecasting equation for this model is: $x(t)=2+x(t-12)+\Phi\{x(t-1)-x(t-12)\}-$ $\theta \mathrm{e}(\mathrm{t}-1)-\Theta \mathrm{e}(\mathrm{t}-12)+\theta \Theta \mathrm{e}(\mathrm{t}-13)$ 
Table 4. contd.

\begin{tabular}{llcccccc}
\hline & $(0,1,1) \times(0,1,1) 12$ & 18.9 & 10 & - & 0.2025 & -2.2682 & -3.723 \\
April & $(0,0,0) \times(0,1,0) 12$ & - & - & - & - & - & - \\
& $(0,1,0) \times(0,1,0) 12$ & - & - & - & - & - & 1.789 \\
& $(1,0,0) \times(0,1,0) 12$ & 3.5 & 11 & 0.8548 & - & -.2420 & 3.2443 \\
\hline
\end{tabular}

Prediction equation follows SARIMA $(1,0,0) \times(0,1,0) 12$ where the number 12 refers to twelve months as seasonal duration over the year. SAR $(1,0,0) \times(0,1,0) 12$ is a seasonal random walk model. the forecasting equation is: $x(t)=a+x(t-12)+\Phi(x(t-1)-x(t-12))$. The seasonal random walk(SRW) is an alternate to seasonal random trend (SRT) model

Table 5. SARIMA sampling point $h$ for winter.

\begin{tabular}{|c|c|c|c|c|c|c|c|}
\hline Month & $\begin{array}{c}\text { Seasonal } \\
\text { SARIMA (p.d.q.) }\end{array}$ & $\chi_{0.05}^{2}$ & d.f & $\begin{array}{c}\text { AR (1) } \\
\Phi\end{array}$ & $\begin{array}{c}\text { MA (1) } \\
0 \\
\end{array}$ & $\begin{array}{c}\text { SMA (12) } \\
\Theta \\
\end{array}$ & $\begin{array}{c}\text { Constant } \\
\text { (a) }\end{array}$ \\
\hline \multirow{5}{*}{ February } & $(0,1,1) \times(0,1,1) 12$ & 10.8 & 10 & - & 0.2454 & -1.9938 & 0.4132 \\
\hline & $(0,0,0) \times(0,1,0) 12$ & - & - & - & - & - & - \\
\hline & $(0,1,0) \times(0,1,0) 12$ & - & - & - & - & - & - \\
\hline & $(1,0,0) \times(0,1,0) 12$ & 5.3 & 11 & 0.3136 & - & - & -0.3112 \\
\hline & $(1,0,1) \times(0,1,1) 12$ & 5.6 & 9 & -0.6958 & -1.175 & 0.2871 & -0.1754 \\
\hline
\end{tabular}

Prediction equation follows SARIMA $(1,0,0) \times(0,1,0) 12$ where the number 12 refers to twelve months as seasonal duration over the year. SAR $(1,0,0) \times(0,1,0) 12$ is a seasonal random walk model. The forecasting equation is: $x(t)=a+x(t-$ $12)+\Phi(x(t-1)-x(t-12))$. The seasonal random walk(SRW) is an alternate to seasonal random trend (SRT) model

\begin{tabular}{cccccccc}
\hline \multirow{4}{*}{ March } & $(0,1,1) \times(0,1,1) 12$ & 19.6 & 10 & - & 9.182 & - & 0.04549 \\
& $(0,0,0) \times(0,1,0) 12$ & - & - & - & - & - & - \\
& $(0,1,0) \times(0,1,0) 12$ & - & - & - & - & - & - \\
& $(1,0,0) \times(0,1,0) 12$ & 10.9 & 11 & -0.3918 & - & - & -0.00698 \\
& $(1,0,1) \times(0,1,1) 12$ & 6.6 & 9 & -0.2276 & 1.1200 & - & -0.00668 \\
\hline
\end{tabular}

Prediction equation follows SARIMA $(1,0,0) \times(0,1,0) 12$ where the number 12 is an important version of seasonal exponential smoothing (SES) model, that is, with a constant. The forecasting equation for this model is: $x(t)=2+x(t-12)+$ $\Phi\{x(t-1)-x(t-12)\}-\theta e(t-1)-\Theta e(t-12)+\theta \Theta e(t-13)$

\begin{tabular}{cccccccc}
\hline & $(0,1,1) \times(0,1,1) 12$ & 18.9 & 10 & - & 0.2025 & -2.2682 & -3.723 \\
\multirow{4}{*}{ April } & $(0,0,0) \times(0,1,0) 12$ & - & - & - & - & - & - \\
& $(0,1,0) \times(0,1,0) 12$ & - & - & - & - & - & - \\
& $(1,0,0) \times(0,1,0) 12$ & 3.5 & 11 & 0.8548 & - & - & 1.789 \\
& $(1,0,1) \times(0,1,1) 12$ & 6.8 & 9 & 0.7796 & -0.0034 & 1.2420 & 3.2443 \\
\hline
\end{tabular}

Prediction equation follows SARIMA $(1,0,0) \times(0,1,0) 12$ where the number 12 refers to twelve months as seasonal duration over the year. SAR $(1,0,0) \times(0,1,0) 12$ is a seasonal random walk model. the forecasting equation is: $x(t)=a+x(t-$ $12)+\Phi(x(t-1)-x(t-12))$. The seasonal random walk(SRW) is an alternate to seasonal random trend (SRT) model

$\theta e(t-1)-\Theta e(t-12)+\Theta \theta e(t-13)$, June $x(t)=a+x(t-12)+\Phi(x(t-$ 1) $-\mathrm{x}(\mathrm{t}-12))$ and July $\mathrm{x}(\mathrm{t})=\mathrm{a}+\mathrm{x}(\mathrm{t}-12)+\Phi\{\mathrm{x}(\mathrm{t}-1)-\mathrm{x}(\mathrm{t}-12)\}-\theta \mathrm{e}(\mathrm{t}-$ 1)- $\Theta e(t-R)+\theta \Theta e(t-13)]$; autumn (Table 8) [August $\mathrm{x}(\mathrm{t})=\mathrm{x}(\mathrm{t}-12)+\mathrm{x}(\mathrm{t}-1)-\mathrm{x}(\mathrm{t}-13)-\theta \mathrm{e}(\mathrm{t}-1)-\Theta \mathrm{e}(\mathrm{t}-12)+\Theta \theta \mathrm{e}(\mathrm{t}-13)$,

September $x(t)=a+x(t-12)+\Phi\{x(t-1)-x(t-12)\}-\theta e(t-1)-\Theta e(t-$ $\mathrm{R})+\theta \Theta e(\mathrm{t}-13)$ and October $\mathrm{x}(\mathrm{t})=\mathrm{a}+\mathrm{x}(\mathrm{t}-12)+\Phi\{\mathrm{x}(\mathrm{t}-1)-\mathrm{x}(\mathrm{t}-$ $12)\}-\theta e(t-1)-\Theta e(t-R)+\theta \Theta e(t-13)]$, and winter are (Table
9) $[$ November $\mathrm{x}(\mathrm{t})=\mathrm{x}(\mathrm{t}-12)+\mathrm{x}(\mathrm{t}-1)-\mathrm{x}(\mathrm{t}-13)-\theta \mathrm{e}(\mathrm{t}-1)-\Theta \mathrm{e}(\mathrm{t}-12)+$ $\Theta \theta e(t-13)$, December $x(t)=a+x(t-12)+\Phi\{x(t-1)-x(t-12)\}-$ $\theta e(t-1)-\Theta e(t-R)+\theta \Theta e(t-13)$ and January $x(t)=x(t-12)+x(t-$ 1) $-\mathrm{x}(\mathrm{t}-13)-\theta \mathrm{e}(\mathrm{t}-1)-\Theta \mathrm{e}(\mathrm{t}-12)+\Theta \theta \mathrm{e}(\mathrm{t}-13)]$ respectively.

Finally, the statistical modeling of SARIMA prediction equations of dust fall of the moderate site of Quetta city, that is, the ' $d$ ' site follow the order: Spring (Table 10) 
Table 6. SARIMA sampling point $f$ for spring.

\begin{tabular}{|c|c|c|c|c|c|c|c|}
\hline Month & $\begin{array}{c}\text { Seasonal SARIMA } \\
\text { (p.d.q.) }\end{array}$ & $\chi_{0.05}^{2}$ & d.f & $\begin{array}{c}A R(1) \\
\Phi\end{array}$ & $\begin{array}{c}\text { MA (1) } \\
\Theta\end{array}$ & $\begin{array}{c}\text { SMA (12) } \\
0\end{array}$ & $\begin{array}{l}\text { Constant } \\
\text { (a) }\end{array}$ \\
\hline \multirow{5}{*}{ February } & $(0,1,1) \times(0,1,1) 12$ & 10.8 & 10 & - & 0.2454 & -1.9938 & 0.4132 \\
\hline & $(0,0,0) \times(0,1,0) 12$ & - & - & - & - & - & - \\
\hline & $(0,1,0) \times(0,1,0) 12$ & - & - & - & - & - & - \\
\hline & $(1,0,0) \times(0,1,0) 12$ & 5.3 & 11 & 0.3136 & - & - & -0.3112 \\
\hline & $(1,0,1) \times(0,1,1) 12$ & 5.6 & 9 & -0.6958 & -1.175 & 0.2871 & -0.1754 \\
\hline
\end{tabular}

Prediction equation follows SARIMA $(1,0,0) \times(0,1,0) 12$ where the number 12 refers to twelve months as seasonal duration over the year. SAR $(1,0,0) \times(0,1,0) 12$ is a seasonal random walk model. The forecasting equation is: $x(t)=a+x(t-12)+\Phi(x(t-$ $1)-x(t-12))$. The seasonal random walk(SRW) is an alternate to seasonal random trend (SRT) model

\begin{tabular}{|c|c|c|c|c|c|c|c|}
\hline & $(0,1,1) \times(0,1,1) 12$ & 19.6 & 10 & - & 9.182 & - & 0.04549 \\
\hline & $(0,0,0) \times(0,1,0) 12$ & - & - & - & - & - & - \\
\hline \multirow[t]{3}{*}{ March } & $(0,1,0) \times(0,1,0) 12$ & - & - & - & - & - & - \\
\hline & $(1,0,0) \times(0,1,0) 12$ & 10.9 & 11 & -0.3918 & - & - & -0.00698 \\
\hline & $(1,0,1) \times(0,1,1) 12$ & 6.6 & 9 & -0.2276 & 1.1200 & - & -0.00668 \\
\hline \multicolumn{8}{|c|}{$\begin{array}{l}\text { Prediction equation follows SARIMA }(1,0,0) \times(0,1,0) 12 \text { where the number } 12 \text { is an important version of seasonal } \\
\text { exponential smoothing (SES) model, that is, with a constant. The forecasting equation for this model is: } \mathrm{x}(\mathrm{t})=2+\mathrm{x}(\mathrm{t}-12)+ \\
\qquad\{\mathrm{x}(\mathrm{t}-1)-\mathrm{x}(\mathrm{t}-12)\}-\theta \mathrm{e}(\mathrm{t}-1)-\Theta \mathrm{e}(\mathrm{t}-12)+\theta \Theta \mathrm{e}(\mathrm{t}-13)\end{array}$} \\
\hline \multirow{5}{*}{ April } & $(0,1,1) \times(0,1,1) 12$ & 18.9 & 10 & - & 0.2025 & -2.2682 & -3.723 \\
\hline & $(0,0,0) \times(0,1,0) 12$ & - & - & - & - & - & - \\
\hline & $(0,1,0) \times(0,1,0) 12$ & - & - & - & - & - & - \\
\hline & $(1,0,0) \times(0,1,0) 12$ & 3.5 & 11 & 0.8548 & - & - & 1.789 \\
\hline & $(1,0,1) \times(0,1,1) 12$ & 6.8 & 9 & 0.7796 & -0.0034 & 1.2420 & 3.2443 \\
\hline
\end{tabular}

Prediction equation follows SARIMA $(1,0,0) \times(0,1,0) 12$ where the number 12 refers to twelve months as seasonal duration over the year. SAR $(1,0,0) \times(0,1,0) 12$ is a seasonal random walk model. The forecasting equation is: $x(t)=a+x(t-12)+\Phi(x(t-$ $1)-x(t-12))$. The seasonal random walk(SRW) is an alternate to seasonal random trend (SRT) model

Table 7. SARIMA sampling point $\mathrm{f}$ for summer.

\begin{tabular}{|c|c|c|c|c|c|c|c|}
\hline Month & $\begin{array}{c}\begin{array}{c}\text { Seasonal SARIMA } \\
\text { (p.d.q.) }\end{array} \\
\end{array}$ & $\chi^{2}{ }_{0.05}$ & d.f & $\begin{array}{c}\text { AR (1) } \\
\Phi\end{array}$ & $\begin{array}{c}\text { MA (1) } \\
\Theta \\
\end{array}$ & $\begin{array}{c}\text { SMA (12) } \\
\Theta \\
\end{array}$ & $\begin{array}{c}\text { Constant } \\
\text { (a) }\end{array}$ \\
\hline \multirow{5}{*}{ February } & $(0,1,1) \times(0,1,1) 12$ & 10.8 & 10 & - & 0.2454 & -1.9938 & 0.4132 \\
\hline & $(0,0,0) \times(0,1,0) 12$ & - & - & - & - & - & - \\
\hline & $(0,1,0) \times(0,1,0) 12$ & - & - & - & - & - & - \\
\hline & $(1,0,0) \times(0,1,0) 12$ & 5.3 & 11 & 0.3136 & - & - & -0.3112 \\
\hline & $(1,0,1) \times(0,1,1) 12$ & 5.6 & 9 & -0.6958 & -1.175 & 0.2871 & -0.1754 \\
\hline
\end{tabular}

Prediction equation follows SARIMA $(1,0,0) \times(0,1,0) 12$ where the number 12 refers to twelve months as seasonal duration over the year. SAR $(1,0,0) \times(0,1,0) 12$ is a seasonal random walk model. The forecasting equation is: $x(t)=a+x(t-12)+\Phi(x(t-1)-x(t-12))$. The seasonal random walk(SRW) is an alternate to seasonal random trend (SRT) model

\begin{tabular}{lllccccc}
\hline \multirow{3}{*}{ March } & $(0,1,1) \times(0,1,1) 12$ & 19.6 & 10 & - & 9.182 & - & 0.04549 \\
& $(0,0,0) \times(0,1,0) 12$ & - & - & - & - & - & - \\
& $(0,1,0) \times(0,1,0) 12$ & - & - & - & - & - & - \\
& $(1,0,0) \times(0,1,0) 12$ & 10.9 & 11 & -0.3918 & - & - & -0.0698 \\
& $(1,0,1) \times(0,1,1) 12$ & 6.6 & 9 & -0.2276 & 1.1200 & - & -0.00668 \\
\hline
\end{tabular}

Prediction equation follows SARIMA $(1,0,0) \times(0,1,0) 12$ where the number 12 is an important version of seasonal exponential smoothing (SES) model, that is, with a constant. The forecasting equation for this model is: $x(t)=2+x(t-12)+\Phi\{x(t-1)-x(t-12)\}-\theta$ $\mathrm{e}(\mathrm{t}-1)-\Theta \mathrm{e}(\mathrm{t}-12)+\theta \Theta e(\mathrm{t}-13)$ 
Table 7. contd.

\begin{tabular}{|c|c|c|c|c|c|c|c|}
\hline \multirow{5}{*}{ April } & $(0,1,1) \times(0,1,1) 12$ & 18.9 & 10 & - & 0.2025 & -2.2682 & -3.723 \\
\hline & $(0,0,0) \times(0,1,0) 12$ & - & - & - & - & - & - \\
\hline & $(0,1,0) \times(0,1,0) 12$ & - & - & - & - & - & - \\
\hline & $(1,0,0) \times(0,1,0) 12$ & 3.5 & 11 & 0.8548 & - & - & 1.789 \\
\hline & $(1,0,1) \times(0,1,1) 12$ & 6.8 & 9 & 0.7796 & -0.0034 & 1.2420 & 3.2443 \\
\hline
\end{tabular}

Prediction equation follows SARIMA $(1,0,0) \times(0,1,0) 12$ where the number 12 refers to twelve months as seasonal duration over the year. SAR $(1,0,0) \times(0,1,0) 12$ is a seasonal random walk model. the forecasting equation is: $x(t)=a+x(t-12)+\Phi(x(t-1)-x(t-12))$. The seasonal random walk(SRW) is an alternate to seasonal random trend (SRT) model

Table 8. SARIMA sampling point $f$ for autumn.

\begin{tabular}{|c|c|c|c|c|c|c|c|}
\hline Month & $\begin{array}{c}\text { Seasonal SARIMA } \\
\text { (p.d.q.) }\end{array}$ & $\chi_{0.05}^{2}$ & d.f & $\begin{array}{c}\text { AR(1) } \\
\Phi \\
\end{array}$ & $\begin{array}{c}\mathrm{MA}(1) \\
\Theta \\
\end{array}$ & $\begin{array}{c}\text { SMA(12) } \\
0 \\
\end{array}$ & Constant (a) \\
\hline \multirow{5}{*}{ August } & $(0,1,1) \times(0,1,1) 12$ & 6.4 & 10 & - & 0.9228 & 0.4267 & -0.1214 \\
\hline & $(0,0,0) \times(0,1,0) 12$ & - & - & - & - & - & - \\
\hline & $(0,1,0) \times(0,1,0) 12$ & - & - & - & - & - & - \\
\hline & $(1,0,0) \times(0,1,0) 12$ & 8.4 & 11 & 0.0783 & - & - & 0.0308 \\
\hline & $(1,0,1) \times(0,1,1) 12$ & 7.5 & 9 & 0.7843 & 0.5747 & 0.5323 & -0.0569 \\
\hline
\end{tabular}

Prediction equation for SARIMA $(0,1,1) \times(0,1,1) 12$ is a seasonal experimental smoothing (SES) model. The forecasting equation for this model is $x(t)=x(t-12)+x(t-1)-x(t-13)-\theta e(t-1)-\Theta e(t-12)+\Theta \theta e(t-13)$ where little $\theta$ is the MA $(1)$ coefficient and big $\Theta$ is the SMA $(1)$ coefficient

\begin{tabular}{cccccccc} 
& $(0,1,1) \times(0,1,1) 12$ & 14.2 & 10 & - & 0.9354 & -0.6338 & -0.00072 \\
\multirow{5}{*}{ September } & $(0,0,0) \times(0,1,0) 12$ & - & - & - & - & - & - \\
& $(0,1,0) \times(0,1,0) 12$ & - & - & - & - & - \\
& $(1,0,0) \times(0,1,0) 12$ & 25.9 & 11 & -0.3257 & - & - & -0.0104 \\
& $(1,0,1) \times(0,1,1) 12$ & 12.8 & 9 & -0.0504 & 0.8861 & -0.7879 & -0.0035
\end{tabular}

Prediction equation for SARIMA $(0,1,1) \times(0,1,1) 12$ is a very important version of seasonal experimental smoothing (SES) model, that is, with a constant. The forecasting equation for this model is $\mathrm{x}(\mathrm{t})=\mathrm{a}+\mathrm{x}(\mathrm{t}-12)+\Phi\{\mathrm{x}(\mathrm{t}-1)-\mathrm{x}(\mathrm{t}-12)\}-\theta \mathrm{e}(\mathrm{t}-1)-\Theta e(\mathrm{t}-\mathrm{R})+\theta \Theta \mathrm{e}(\mathrm{t}-13)$ where the little $\theta$ is MA(1) coefficient and the big $\Theta$ is the $\operatorname{SMA}(1)$ coefficient.

\begin{tabular}{|c|c|c|c|c|c|c|c|}
\hline & $(0,1,1) \times(0,1,1) 12$ & 12.8 & 10 & - & 0.9257 & -0.7875 & 6.937 \\
\hline & $(0,0,0) \times(0,1,0) 12$ & - & - & - & - & - & - \\
\hline \multirow[t]{3}{*}{ October } & $(0,1,0) \times(0,1,0) 12$ & - & - & - & - & - & - \\
\hline & $(1,0,0) \times(0,1,0) 12$ & 14.2 & 11 & 0.1771 & - & - & -14.44 \\
\hline & $(1,0,1) \times(0,1,1) 12$ & 13.0 & 9 & 0.6527 & 0.4474 & -0.0742 & -6.11 \\
\hline
\end{tabular}

Prediction equation for SARIMA $(0,1,1) \times(0,1,1) 12$ is a very important version of seasonal experimental smoothing (SES) model, that is, with a constant. The forecasting equation for this model is $\mathrm{x}(\mathrm{t})=\mathrm{a}+\mathrm{x}(\mathrm{t}-12)+\Phi\{\mathrm{x}(\mathrm{t}-1)-\mathrm{x}(\mathrm{t}-12)\}-\theta \mathrm{e}(\mathrm{t}-1)-\Theta e(\mathrm{t}-\mathrm{R})+\theta \Theta \mathrm{e}(\mathrm{t}-13)$ where the little $\theta$ is MA(1) coefficient and the big $\Theta$ is the SMA(1) coefficient.

[February $\quad \mathrm{x}(\mathrm{t})=\mathrm{a}+\mathrm{x}(\mathrm{t}-12)+\Phi(\mathrm{x}(\mathrm{t}-1)-\mathrm{x}(\mathrm{t}-12)), \quad$ March $x(t)=a+x(t-12)+\Phi(x(t-2)-x(t-12))-\theta e(t-1)-\Theta e(t-12)+\theta \Theta e(t-$ 13) and April $x(t)=a+x(t-12)+\Phi(x(t-1)-x(t-12))]$; summer (Table 11) [May $\mathrm{x}(\mathrm{t})=\mathrm{a}+\mathrm{x}(\mathrm{t}-12)+\Phi(\mathrm{x}(\mathrm{t}-2)-\mathrm{x}(\mathrm{t}-12))-\theta \mathrm{e}(\mathrm{t}-1)-$ $\Theta e(t-12)+\theta \Theta e(t$ 13); June $x(t)=a+x(t-12)+\Phi(x(t-2)-x(t-12))-$ $\theta e(\mathrm{t}-1)-\Theta e(\mathrm{t}-12)+\theta \Theta e(\mathrm{t}-13)$, and July $\mathrm{x}(\mathrm{t})=\mathrm{a}+\mathrm{x}(\mathrm{t}-$ $12)+\Phi(\mathrm{x}(\mathrm{t}-2)-\mathrm{x}(\mathrm{t}-12))-\theta \mathrm{e}(\mathrm{t}-1)-\Theta \mathrm{e}(\mathrm{t}-12)+\theta \Theta \mathrm{e}(\mathrm{t}-13)]$;

autumn (Table 12) [August $\mathrm{x}(\mathrm{t})=\mathrm{a}+\mathrm{x}(\mathrm{t}-12)+\Phi(\mathrm{x}(\mathrm{t}-2)-\mathrm{x}(\mathrm{t}-$
12) $)-\theta e(t-1)-\Theta e(t-12)+\theta \Theta e(t-13)$, September $x(t)=a+x(t-$ $12)+\Phi(x(t-1)-x(t-12))$ and October $x(t)=a+x(t-12)+\Phi(x(t-1)-$ $\mathrm{x}(\mathrm{t}-12))$ ], and winter (Table 13) [November $\mathrm{x}(\mathrm{t})=\mathrm{x}(\mathrm{t}-$ $12)=(x(t-1)-x(t-13))-\theta e(t-1)-\Theta e(t-12)+\Theta \theta e(t-13)$,

December $\quad x(t)=a+x(t-12)+\Phi(x(t-2)-x(t-12))-\theta e(t-1)-\Theta e(t-$ 12) $+\theta \Theta e(t-13)$ and January $x(t)=a+x(t-12)+\Phi(x(t-2)-x(t-$ 12) $)-\theta e(t-1)-\Theta e(t-12)+\theta \Theta e(t-13)]$.

The prediction equations of SARIMA, if correlated 
Table 9. SARIMA sampling point $f$ for winter.

\begin{tabular}{lccccccc}
\hline \multirow{2}{*}{ Month } & $\begin{array}{c}\text { Seasonal SARIMA } \\
\text { (p.d.q.) }\end{array}$ & \multirow{2}{*}{$\chi^{2}{ }_{0.05}$} & d.f & AR (1) & \multicolumn{2}{c}{ MA (1) } & \multicolumn{2}{c}{$\begin{array}{c}\text { SMA (12) } \\
\boldsymbol{\Theta}\end{array}$} & $\begin{array}{c}\text { Constant } \\
\text { (a) }\end{array}$ \\
\hline \multirow{3}{*}{ November } & $(0,1,1) \times(0,1,1) 12$ & 6.9 & 10 & - & -0.2058 & 0.1953 & -1.074 \\
& $(0,0,0) \times(0,1,0) 12$ & - & - & - & - & - & - \\
& $(0,1,0) \times(0,1,0) 12$ & - & - & - & - & - & - \\
& $(1,0,0) \times(0,1,0) 12$ & 10.7 & 11 & 0.6850 & - & 0.144 \\
& $(1,0,1) \times(0,1,1) 12$ & 8.5 & 9 & 0.5787 & -0.3400 & 0.2301 & -0.042 \\
\hline
\end{tabular}

Prediction equation for SARIMA $(0,1,1) \times(0,1,1) 12$ is a seasonal experimental smoothing (SES) model. The forecasting equation for this model is: $x(t)=x(t-12)+x(t-1)-x(t-13)-\theta e(t-1)-\Theta e(t-12)+\Theta \theta e(t-13)$ where little $\theta$ is the $M A(1)$ coefficient and big $\Theta$ is the SMA(1) coefficient.

\begin{tabular}{cccccccc} 
& $(0,1,1) \times(0,1,1) 12$ & 3.9 & 10 & - & 0.9388 & 0.2434 & 0.2074 \\
\multirow{5}{*}{ December } & $(0,0,0) \times(0,1,0) 12$ & - & - & - & - & - & - \\
& $(0,1,0) \times(0,1,0) 12$ & - & - & - & - & - & -0.9149 \\
& $(1,0,0) \times(0,1,0) 12$ & 4.1 & 11 & -0.0792 & - & - & - \\
& $(1,0,1) \times(0,1,1) 12$ & 3.3 & 9 & -0.5896 & 0.4893 & 0.6349 & -1.1108 \\
\hline
\end{tabular}

Prediction equation for SARIMA $(0,1,1) \times(0,1,1) 12$ is a very important version of seasonal experimental smoothing (SES) model, that is, with a constant. The forecasting equation for this model is: $\mathrm{x}(\mathrm{t})=\mathrm{a}+\mathrm{x}(\mathrm{t}-12)+\Phi\{\mathrm{x}(\mathrm{t}-1)-\mathrm{x}(\mathrm{t}-12)\}-\theta e(\mathrm{t}-1)-\Theta e(\mathrm{t}-\mathrm{R})+\theta \Theta e(\mathrm{t}-13)$ where the little $\theta$ is $M A(1)$ coefficient and the big $\Theta$ is the $\operatorname{SMA}(1)$ coefficient.

$\begin{array}{ccccccc}(0,1,1) \times(0,1,1) 12 & 9.9 & 11 & - & 0.8075 & 0.9024 & 0.06362 \\ (0,0,0) \times(0,1,0) 12 & - & - & - & - & - & - \\ (0,1,0) \times(0,1,0) 12 & - & - & - & - & - & - \\ (1,0,0) \times(0,1,0) 12 & 18.2 & 11 & -0.4245 & - & - & 0.2803 \\ (1,0,1) \times(0,1,1) 12 & 10.8 & 9 & 0.1932 & 0.6495 & 1.0253 & -0.05185\end{array}$

Prediction equation for SARIMA $(0,1,1) \times(0,1,1) 12$ is a seasonal experimental smoothing (SES) model. The forecasting equation for this model is: $x(t)=x(t-12)+x(t-1)-x(t-13)-\theta e(t-1)-\Theta e(t-12)+\Theta \theta e(t-13)$ where little $\theta$ is the $M A(1)$ coefficient and big $\Theta$ is the SMA(1) coefficient.

Table 10. SARIMA sampling point $d$ for spring.

\begin{tabular}{|c|c|c|c|c|c|c|c|}
\hline Month & $\begin{array}{c}\text { Seasonal } \\
\text { SARIMA (p.d.q.) }\end{array}$ & $\chi_{0.05}^{2}$ & d.f & $\begin{array}{c}\text { AR (1) } \\
\Phi\end{array}$ & $\begin{array}{c}\text { MA (1) } \\
0\end{array}$ & $\begin{array}{c}\text { SMA (12) } \\
\Theta \\
\end{array}$ & Constant (a) \\
\hline \multirow{5}{*}{ November } & $(0,1,1) \times(0,1,1) 12$ & 6.9 & 10 & - & -0.2058 & 0.1953 & -1.074 \\
\hline & $(0,0,0) \times(0,1,0) 12$ & - & - & - & - & - & - \\
\hline & $(0,1,0) \times(0,1,0) 12$ & - & - & - & - & - & - \\
\hline & $(1,0,0) \times(0,1,0) 12$ & 10.7 & 11 & 0.6850 & - & - & 0.144 \\
\hline & $(1,0,1) \times(0,1,1) 12$ & 8.5 & 9 & 0.5787 & -0.3400 & 0.2301 & -0.042 \\
\hline
\end{tabular}

Prediction equation for SARIMA $(0,1,1) \times(0,1,1) 12$ is a seasonal experimental smoothing (SES) model. The forecasting equation for this model is: $x(t)=x(t-12)+x(t-1)-x(t-13)-\theta e(t-1)-\Theta e(t-12)+\Theta \theta e(t-13)$ where little $\theta$ is the MA $(1)$ coefficient and big $\Theta$ is the SMA(1) coefficient

\begin{tabular}{lllllccc}
\hline & $(0,1,1) \times(0,1,1) 12$ & 3.9 & 10 & - & 0.9388 & 0.2434 & 0.2074 \\
& $(0,0,0) \times(0,1,0) 12$ & - & - & - & - & - & - \\
December & $(0,1,0) \times(0,1,0) 12$ & - & - & - & - & - & -0.9149 \\
& $(1,0,0) \times(0,1,0) 12$ & 4.1 & 11 & -0.0792 & - & - & -1.1108 \\
\hline
\end{tabular}

Prediction equation for SARIMA $(0,1,1) \times(0,1,1) 12$ is a very important version of seasonal experimental smoothing (SES) model, that is, with a constant. The forecasting equation for this model is: $\mathrm{x}(\mathrm{t})=\mathrm{a}+\mathrm{x}(\mathrm{t}-12)+\Phi\{\mathrm{x}(\mathrm{t}-1)-\mathrm{x}(\mathrm{t}-12)\}-\theta \mathrm{e}(\mathrm{t}-1)-\Theta e(\mathrm{t}-\mathrm{R})+\theta \Theta e(\mathrm{t}-13)$ where the little $\theta$ is MA(1) coefficient and the big $\Theta$ is the SMA(1) coefficient 
Table 10. contd.

\begin{tabular}{llcccccc}
\hline \multirow{5}{*}{ January } & $(0,1,1) \times(0,1,1) 12$ & 9.9 & 11 & - & 0.8075 & 0.9024 & 0.06362 \\
& $(0,0,0) \times(0,1,0) 12$ & - & - & - & - & - & - \\
& $(0,1,0) \times(0,1,0) 12$ & - & - & - & - & - & - \\
& $(1,0,0) \times(0,1,0) 12$ & 18.2 & 11 & -0.4245 & - & 0.2803 & - \\
& $(1,0,1) \times(0,1,1) 12$ & 10.8 & 9 & 0.1932 & 0.6495 & 1.0253 & -0.05185 \\
\hline
\end{tabular}

Prediction equation for SARIMA $(0,1,1) \times(0,1,1) 12$ is a seasonal experimental smoothing (SES) model. The forecasting equation for this model is: $x(t)=x(t-12)+x(t-1)-x(t-13)-\theta e(t-1)-\Theta e(t-12)+\Theta \theta e(t-13)$ where little $\theta$ is the $M A(1)$ coefficient and big $\Theta$ is the SMA(1) coefficient

Table 11. SARIMA sampling point $d$ for summer.

\begin{tabular}{|c|c|c|c|c|c|c|c|}
\hline Month & $\begin{array}{c}\text { Seasonal SARIMA } \\
\text { (p.d.q.) }\end{array}$ & $\chi^{2}{ }_{0.05}$ & d.f & $\begin{array}{c}\text { AR (1) } \\
\Phi\end{array}$ & $\begin{array}{c}\text { MA (1) } \\
0 \\
\end{array}$ & $\begin{array}{c}\text { SMA (12) } \\
\ominus \\
\end{array}$ & Constant (a) \\
\hline \multirow{5}{*}{ May } & $(0,1,1) \times(0,1,1) 12$ & 4.4 & 10 & - & 0.8150 & 0.2976 & 0.532 \\
\hline & $(0,0,0) \times(0,1,0) 12$ & - & - & - & - & - & - \\
\hline & $(0,1,0) \times(0,1,0) 12$ & - & - & - & - & - & - \\
\hline & $(1,0,0) \times(0,1,0) 12$ & 13.9 & 11 & -0.2075 & - & - & 10.804 \\
\hline & $(1,0,1) \times(0,1,1) 12$ & 7.4 & 9 & 0.2069 & 0.4678 & 0.6396 & 7.491 \\
\hline
\end{tabular}

SARIMA $(1,0,1) \times(0,1,1) 12$ is an important version of SES model, that is, with a constant. The forecasting equation for this model is: $x(t)=a+x(t-12)+\Phi(x(t-2)-x(t-12))-\theta e(t-1)-\Theta e(t-12)+\theta \Theta e(t-13)$ where $a$ is a constant, $\Theta=S M A(12)$ and $e$ is the error term

\begin{tabular}{llcccccc}
\hline & $(0,1,1) \times(0,1,1) 12$ & 22.4 & 10 & - & 0.8637 & 1.0756 & 0.1396 \\
June & $(0,0,0) \times(0,1,0) 12$ & - & - & - & - & - \\
& $(0,1,0) \times(0,1,0) 12$ & - & - & - & - & - \\
& $(1,0,0) \times(0,1,0) 12$ & 15.5 & 11 & -0.2370 & - & - & 0.1221 \\
& $(1,0,1) \times(0,1,1) 12$ & 1.8 & 9 & -0.0907 & 0.8196 & 1.2202 & 0.08225 \\
\hline
\end{tabular}

SARIMA $(1,0,1) \times(0,1,1) 12$ is an important version of SES model, that is, with a constant. The forecasting equation for this model is: $\mathrm{x}(\mathrm{t})=\mathrm{a}+\mathrm{x}(\mathrm{t}-12)+\Phi(\mathrm{x}(\mathrm{t}-2)-\mathrm{x}(\mathrm{t}-12))-\theta \mathrm{e}(\mathrm{t}-1)-\Theta e(\mathrm{t}-12)+\theta \Theta e(\mathrm{t}-13)$ where $\mathrm{a}$ is a constant, $\Theta=S M A(12)$ and $\mathrm{e}$ is the error term.

\begin{tabular}{llcccccc} 
& & & & & & \\
\multirow{3}{*}{ July } & $(0,1,1) \times(0,1,1) 12$ & 11.4 & 10 & - & 0.8080 & 2.5203 & - \\
& $(0,0,0) \times(0,1,0) 12$ & - & - & - & - & - & - \\
& $(0,1,0) \times(0,1,0) 12$ & - & - & - & - & - & -0.0999 \\
& $(1,0,0) \times(0,1,0) 12$ & 10.1 & 11 & -0.3670 & - & -0.01776 \\
\hline
\end{tabular}

SARIMA $(1,0,1) \times(0,1,1) 12$ is an important version of SES model, that is, with a constant. The forecasting equation for this model is: $x(t)=a+x(t-12)+\Phi(x(t-2)-x(t-12))-\theta e(t-1)-\Theta e(t-12)+\theta \Theta e(t-13)$ where $a$ is a constant, $\Theta=S M A(12)$ and $e$ is the error term.

analytically, would also provide a rationale such as diurnal variations for shorter lead times. For this reason, a different statistical analysis is needed which may be a logistic regression analysis or logit. We can also accomplish a multivariate analysis of parameters of both ARIMA and SARIMA. Therefore, there is a dire need to evolve hybrid models such as mixing ARIMA and SARIMA with any expert system (Intelligent System) to inculcate minor diurnal variations, the noise effect and the corresponding sporadic variations. The diurnal variations (cyclic stochastic components) should thus, be incorporated in a model development such as in ARIMA and SARIMA.
Modeling and simulation of asymptotic departure (optimum variations) from randomness needed to be developed. This would help to resolve the optimum dust fall rate for each location in Quetta.

The division of trace elements cannot be detached from that of particulates size, specifically, $\mathrm{PM}_{2.5-5.0}$ and $\mathrm{PM}_{<1.0}$, scattered in the atmosphere. Therefore a correlative and multivariate statistics having all data could be applied to find out the correlation between toxic elements connected with peculiar sizes and shapes of dust particulates, and to explore in more detail the local atmosphere which is undergoing remarkable anthropogenic translocations.

Zeolites, which are widely used in the modern period as 
Table 12. SARIMA sampling point $d$ for autumn.

\begin{tabular}{|c|c|c|c|c|c|c|c|}
\hline Month & $\begin{array}{c}\text { Seasonal } \\
\text { SARIMA (p.d.q.) }\end{array}$ & $\chi_{0.05}^{2}$ & d.f & $\begin{array}{c}\text { AR (1) } \\
\Phi\end{array}$ & $\begin{array}{c}\text { MA (1) } \\
\Theta\end{array}$ & $\begin{array}{c}\text { SMA (12) } \\
\ominus\end{array}$ & $\begin{array}{l}\text { Constant } \\
\text { (a) }\end{array}$ \\
\hline \multirow{5}{*}{ August } & $(0,1,1) \times(0,1,1) 12$ & 22.6 & 10 & - & 0.8563 & 0.2284 & -0.0489 \\
\hline & $(0,0,0) \times(0,1,0) 12$ & - & - & - & - & - & - \\
\hline & $(0,1,0) \times(0,1,0) 12$ & - & - & - & - & - & - \\
\hline & $(1,0,0) \times(0,1,0) 12$ & 19.4 & 11 & -0.3402 & - & - & -0.0248 \\
\hline & $(1,0,1) \times(0,1,1) 12$ & 11.3 & 9 & 0.2052 & 0.8079 & 0.2181 & -0.0420 \\
\hline
\end{tabular}

SARIMA $(1,0,1) \times(0,1,1) 12$ is an important version of SES model, that is, with a constant. The forecasting equation for this model is: $\mathrm{x}(\mathrm{t})=\mathrm{a}+\mathrm{x}(\mathrm{t}-12)+\Phi(\mathrm{x}(\mathrm{t}-2)-\mathrm{x}(\mathrm{t}-12))-\theta \mathrm{e}(\mathrm{t}-1)-\Theta e(\mathrm{t}-12)+\theta \Theta e(\mathrm{t}-13)$ where $\mathrm{a}$ is a constant, $\Theta=S M A(12)$ and $e$ is the error term

\begin{tabular}{cccccccc}
\hline & $(0,1,1) \times(0,1,1) 12$ & 23.6 & 10 & - & 0.8872 & 0.4041 & -0.0404 \\
\multirow{5}{*}{ September } & $(0,0,0) \times(0,1,0) 12$ & - & - & - & - & - & - \\
& $(0,1,0) \times(0,1,0) 12$ & - & - & - & - & - & - \\
& $(1,0,0) \times(0,1,0) 12$ & 5.7 & 11 & -0.8179 & - & - & 0.0402 \\
& $(1,0,1) \times(0,1,1) 12$ & 5.9 & 9 & -0.0759 & 0.5090 & 0.7369 & -0.07995 \\
\hline
\end{tabular}

SARIMA $(1,0,0) \times(0,1,0)$ is a seasonal random walk model. The forecasting equation is: $x(t)=a+x(t-12)+\Phi(x(t-1)-x(t-12))$. The seasonal random walk (SRW) is an alternate to seasonal random trend (SRT) model

\begin{tabular}{lccccccc}
\hline \multirow{5}{*}{ October } & $(0,1,1) \times(0,1,1) 12$ & 14.0 & 10 & - & 0.4106 & 0.4892 & -0.01522 \\
& $(0,0,0) \times(0,1,0) 12$ & - & - & - & - & - & - \\
& $(0,1,0) \times(0,1,0) 12$ & - & - & - & - & - & - \\
& $(1,0,0) \times(0,1,0) 12$ & 12.2 & 11 & 0.3736 & - & -066 \\
\hline
\end{tabular}

SARIMA $(1,0,0) \times(0,1,0)$ is a seasonal random walk model. The forecasting equation is: $x(t)=a+x(t-12)+\Phi(x(t-1)-x(t-12))$. The seasonal random walk (SRW) is an alternate to seasonal random trend (SRT) model

Table 13. SARIMA sampling point $d$ for winter.

\begin{tabular}{lccccccc}
\hline \multirow{2}{*}{ Month } & \begin{tabular}{c} 
Seasonal \\
\multirow{2}{*}{ SARIMA (p.d.q.) }
\end{tabular} & \multirow{2}{*}{$\chi^{2}{ }_{0.05}$} & \multirow{2}{*}{ d.f } & AR (1) & \multicolumn{2}{c}{ MA (1) } & \multicolumn{2}{c}{ SMA (12) } & \multirow{2}{*}{ Constant (a) } \\
& $(0,1,1) \times(0,1,1) 12$ & 22.6 & 10 & - & 0.8563 & 0.2284 & -0.0489 \\
\multirow{3}{*}{ August } & $(0,0,0) \times(0,1,0) 12$ & - & - & - & - & - & - \\
& $(0,1,0) \times(0,1,0) 12$ & - & - & - & - & - & -0.0248 \\
& $(1,0,0) \times(0,1,0) 12$ & 19.4 & 11 & -.3402 & - & - & 0.2181 \\
\hline
\end{tabular}

SARIMA $(1,0,1) \times(0,1,1) 12$ is an important version of SES model, that is, with a constant. The forecasting equation for this model is: $x(t)=a+x(t-12)+\Phi(x(t-2)-x(t-12))-\theta e(t-1)-\Theta e(t-12)+\theta \Theta e(t-13)$ where $a$ is a constant, $\Theta=S M A(12)$ and $e$ is the error term.

\begin{tabular}{|c|c|c|c|c|c|c|c|}
\hline \multirow{5}{*}{ September } & $(0,1,1) \times(0,1,1) 12$ & 23.6 & 10 & - & .8872 & .4041 & -0.0404 \\
\hline & $(0,0,0) \times(0,1,0) 12$ & - & - & - & - & - & - \\
\hline & $(0,1,0) \times(0,1,0) 12$ & - & - & - & - & - & - \\
\hline & $(1,0,0) \times(0,1,0) 12$ & 5.7 & 11 & -0.8179 & - & - & 0.0402 \\
\hline & $(1,0,1) \times(0,1,1) 12$ & 5.9 & 9 & -0.0759 & 0.5090 & .7369 & -0.07995 \\
\hline \multicolumn{8}{|c|}{$\begin{array}{l}\text { SARIMA }(1,0,0) \times(0,1,0) \text { is a seasonal random walk model. The forecasting equation is: } x(t)=a+x(t-12)+\Phi(x(t-1)-x(t-12)) \text {. The } \\
\text { seasonal random walk }(S R W) \text { is an alternate to seasonal random trend }(S R T) \text { model. }\end{array}$} \\
\hline \multirow{3}{*}{ October } & $(0,1,1) \times(0,1,1) 12$ & 14.0 & 10 & - & 0.4106 & .4892 & -.1522 \\
\hline & $(0,0,0) \times(0,1,0) 12$ & - & - & - & - & - & - \\
\hline & $(0,1,0) \times(0,1,0) 12$ & - & - & - & - & - & - \\
\hline
\end{tabular}


Table 13. contd.

$\begin{array}{ccccccc}(1,0,0) \times(0,1,0) 12 & 12.2 & 11 & 0.3736 & - & - & 0.066 \\ (1,0,1) \times(0,1,1) 12 & 14.5 & 9 & 0.3506 & -0.1227 & 0.5196 & -0.241\end{array}$

SARIMA $(1,0,0) \times(0,1,0)$ is a seasonal random walk model. The forecasting equation is: $x(t)=a+x(t-12)+\Phi(x(t-1)-x(t-12))$. The seasonal random walk (SRW) is an alternate to seasonal random trend (SRT) model.

scavengers in different industries in order to gain maximum product by avoiding the loss of a major chunk of the costly raw material (for instance in the fractional distillation of petroleum), could also be effectively used in a similar way to clean the environment, particularly, air by finding the effective techniques of their usages for the said vital purpose.

The rate of dust fall in Quetta has been recorded as high due to its geography, and as very high during the twilight of abating drought spell, which emerged infrequently from the regional deserts of Dalbandin (Pakistan) and Dasht-e-Lut (Iran).

Due to the adulteration of fuel, the concentration of $\mathrm{Pb}$ (lead) was found to be so high among other heavy/toxic elements as well.

Lack of industries in the city proved to be a blessing in disguise. In spite of thermal inversion, however, Quetta city did not have disastrous situations as had been witnessed at Donora and London (UK) due to the photochemical smog.

\section{REFERENCES}

Aguiar R, Collares-Pereira M (1992). Time dependent autoregressive gaussian model for generating synthetic hourly radiation. Solar Energy, 49: 167-171.

American Standard Test Method (2004). ASTM D1739 Dust=Milligrams/day/square meter.

Blanchard M, Desrochers G (1984). Generation of auto correlated wind speeds for wind energy conversion system studies. Solar Energy, 33: 571-579.

Box GEP, Jenkins GM (1976). Time Series Analysis, Forecasting and Control, Holden-Day, San Francisco, USA, pp. 341-145.

Brown BG, Kate RW, Murphy AA (1984). Time Series Models to Simulate and Forecast Wind Speed and Wind Power. J. Appl. Meteor., 23: 1184-1195.

Brown BG, Katz RW, Murphy AA, Peterson BA (1982). Time series model for simulating hourly wind power. Rep. No. BPA, DOE /BP154. Dept. Atoms Sci., 51: 82-10.

Chapra SC, Canale RP (1990). Numerical Methods for Engineers. 2nd Ed., McGraw-Hill, Singapore, pp.87-89.

Cragg C, Conway E, Pearsall NM (1999). Stochastic simulation using ARIMA modeling of solar irradiance. Renew. Energy, 18: 445-451.
Durdu OF (2010). Stochastic approaches for time series forecasting of boron: A case study of Western Turkey. Environ. Monit. Assess., 169: 687-701.

Gujarati DN (1988). Basic Econometrics. 2nd Edition, McGraw-Hill, International Edition, Singapore, pp. 172-179.

Hamdi MR, Bdour AN, Tarawneh ZS (2008). Developing reference crop evapotranspiration time series simulation model using class a pan: A case study for the Jordan Valley /Jordan. Jordan J. Earth Environ. Sci. 1: 33-44.

Jafri YZ, Farooqui N, Durrani AU, Raza SM (1989). Estimation of Wind Energy. Solar Wind Technol., 6: 605-609.

Jafri YZ, Sami M, Waseem A, Murtaza G, Akbar S (2012). Stochastic approaches for time series forecasting of rate of dust fall: A case study of North West of Balochistan, Pakistan. Int. J. Phys. Sci., 7(4): 676-686.

Jain PK, Lungu EM (2002). Stochastic models for sunshine duration and solar irradiation. Renew. Energy, 27: 197-203.

Kamal L, Jafri YZ (1996). Simulation of Weibull Distribution of HAWS. Sci. Int., 8: 113-118.

Kamal L, Jafri YZ (1997). Time series models to simulate and forecast hourly averaged wind in Quetta, Pakistan. Solar Energy, 61: 23-32.

Kamal L, Jafri YZ (1999). Stochastic modeling and generation of synthetic sequences of hourly global solar irradiation at Quetta, Pakistan. Renew. Energy, 18: 565-572.

Kumar K, Yadav AK, Singh MP, Hassan H, Jain VK (2004). Forecasting daily maximum surface ozone concentrations in Brunei Darussalam- An ARIMA modelling approach. J. Air Waste Manag. Assoc., 84: 809-814.

Kumar U, Jain VK (2010). ARIMA forecasting of ambient air pollutants $\left(\mathrm{O}_{3}, \mathrm{NO}, \mathrm{NO}_{2}\right.$ and $\left.\mathrm{CO}\right)$ Stoch. Environ. Res. Risk Assess., 24: 751760

McWilliams B, Sprevak D (1982a). The simulation of hourly wind speed and duration. Math. Comp. Simul., 24: 54-59.

McWilliams B, Sprevak D (1982b). Time series models for horizontal wind. Wind Eng., 6: 219-227.

Mora-Lopez LL, Sidrach-de-Cardona M (1998). Multiplicative ARMA models to generate hourly series of solar global irradiance model. Solar Energy, 63: 283-290.

Rawlings JO (1988). Applied Regression Analysis, A Research Tool, Wads wroth and Brooks Inc., Belmont, California, U.S.A., pp. 56-63.

Sami M (2009). PhD Thesis on rate of dust fall and particulates analysis in Quetta, Department of Chemistry, Universityof Balochistan, pp. $112-117$.

Sami M, Waseem A, Akbar S (2006). Quantitative estimation of dust fall and smoke particles in Quetta Valley. JZUSB, 7: 542-547.

Sfetsos AN (2002). A novel approach for the forecasting of mean hourly wind speed time series. Renew. Energy, 27: 163-174. 